\title{
THE ROLE OF GLOBALIZATION IN CHANGING CONSUMPTION PATTERNS: A CASE STUDY OF PUNJAB, PAKISTAN
}

\author{
Atif Khan Jadoon ${ }^{\text {** }}$, Maria Faiq Javaid ${ }^{2}$, Rehan Ahmed Khan Sherwani ${ }^{3}$, Syeda Azra Batool ${ }^{4}$ \\ ${ }^{1 *, 2}$ Assistant Professor, School of Economics, University of the Punjab, Pakistan; ${ }^{3}$ Associate Professor, College of \\ Statistical and Actuarial Sciences, University of the Punjab, Pakistan; ${ }^{4}$ Assistant Professor, School of Economics, \\ Bahauddin Zakariya University, Pakistan. \\ Email: ${ }^{1 *}$ atifkhan.eco@pu.edu.pk, ${ }^{2}$ mariafaiq.eco@pu.edu.pk, ${ }^{3}$ rehan.stat@pu.edu.pk, ${ }^{4}$ azrabatools@yahoo.com \\ Article History: Received on $18^{\text {th }}$ April 2021, Revised on $16^{\text {th }}$ May 2021, Published on $23^{\text {rd }}$ May 2021
}

\begin{abstract}
Purpose of the study: Since the process of globalization is reshaping the thoughts of individuals about the world and creating uniform consumption patterns, the present study is designed to investigate that how globalization is changing the consumption patterns of the people living in Punjab, Pakistan.

Methodology: The present study has collected primary data from the three big cities of Punjab, Pakistan. A quantitative research method is applied to carry out results. Both paper-pencil and web-based methods were used to collect data. Using multistage sampling, sophisticated estimation techniques, such as Confirmatory Factor Analysis (CFA) and Structural Equation Modeling (SEM), are applied to obtain the results.

Main findings: The results of CFA confirm that the variable globalization is constructed with the help of commerce, information communication and technology (ICT), and education while the variable consumption patterns variable is measured with the help of physiological needs, communication needs, and ethnic household consumption. The results of SEM show that globalization is changing the consumption patterns of the individuals living in Punjab, Pakistan.
\end{abstract}

Application of the study: The outcome of the present study shows that globalization through Multinational Corporations (MNCs), ICT, and education is changing the consumption patterns of individuals. This study draws the attention of policymakers to fix the minimum wage rate for workers working in MNCs and compel MNCs to revise their pricing policy.

Novelty/ Originality of the study: The present study is a rare initiative as, to the best of the researcher's knowledge; there is not even a single study that has considered all the dimensions of globalization and consumption patterns. This study is an important contribution as it fulfils various gaps that exist in the existing literature.

Keywords: Globalization, Consumption Patterns, Confirmatory Factor Analysis, Structural Equation Modeling, HigherOrder Model.

\section{INTRODUCTION}

The dawn of the $21^{\text {st }}$ century brought forth the idea of making this world an integrated village. This idea became known as globalization. The notion of globalization is the centre of discussion for intellectuals associated with different fields of social sciences or even for a common man with basic education. Globalization provides more and more countries with a wide variety of goods and services and opportunities to enjoy higher standards of living (Bretos \& Marcuello, 2017; Campbell et al., 2017; Rosokhata, Rybina, Derykolenko, \& Makerska, 2020; Sharma, Nguyen, \& Grote, 2018; Wang, Shi, \& Zhang, 2017). Researchers often argue that the powerful force of market integration is driving the world towards increasing homogeneity. According to Bigman (2002), every country around the globe is experiencing the effects of globalization. With global integration, the consumption patterns of the individuals living in Pakistan are also changing over time. The present study is designed to check how globalization has changed the consumption patterns of the people living in Pakistan.

Globalization is a process where goods, services, money, people, and information flow from one country to another country and creating a unique form of connection among all countries of the world (Ergashev \& Farxodjonova, 2020; Steger, 2017). In another study, Sundaram and Khoo (2003) defined globalization as a transboundary movement of capital, people, goods, information, and culture which spurt into intellectuals during the 1980s and 1990s. While according to Moahi (2007), globalization is an interconnecting world, supporting economic development, providing information and technology, and assisting this world to become a global village. Moreover, Robertson (1992) expounded the various channels like trade, Multinational Cooperation (MNCs), media, and modernization through which globalization is bringing changes in the life of the masses.

One of the prominent effects of globalization can be seen in consumption patterns (food, clothing, beverages, household chores services, health, education, etc.) of the individual (Haidar \& Fang, 2019; Kearney, 2010; Ulucak, Koçak, Erdoğan, \& Kassouri, 2020). Globalization makes consumption patterns increasingly similar from one country to another. Due to the globalization process, the consumption patterns of individuals are becoming homogenous over time (Ardalan, 2009). Moreover, due to the global integration, goods and services produced in one country are readily available in other countries of the world as well. An increased level of international trade is one of the prime reasons for the availability of goods worldwide (Bretos \& Marcuello, 2017; Surugiu \& Surugiu, 2015). In this regard, the MNCs 
have played a vital role as goods produced by MNCs like Unilever, Proctor, and Gamble, McDonald's, Nestle, and Kinley, etc. are used by almost every individual in Pakistan.

The similarity in the provision of goods and services all over the world has brought about uniformity in consumption patterns. With the introduction of international food chains like Kentucky Fried Chicken (KFC), McDonald's, and Pizza Hut in Pakistan, people are consuming more and more fast food and preferring it to traditional food (Islam, Attiq, Hameed, Khokhar, \& Sheikh, 2019; Usman et al., 2017; Yahya, Zafar, \& Shafiq, 2013). Similar trends have been observed in clothing as well where individuals in Pakistan prefer to use branded and western-style clothes (Ali, Khalid, \& Hassan, 2014; Tabish, Hussain, \& Afshan, 2017; Zeb, Rashid, \& Javeed, 2011). With global integration, education systems are becoming homogenous as well. International educational institutions are seen in major cities of Pakistan.

People in Pakistan try to send their children to English medium private schools as these schools are considered superior to Urdu medium (native language). In this regard, Rahman (2006) discussed that the English language in Pakistan is considered a status symbol and is replacing Urdu and other native languages. In this process, the cost of education in the household budget has increased significantly. Information communication and technology (ICT) have also played a significant role in making the world a global village. The term ICT includes television (TV), mobile phones, the internet, computer, and laptop, etc. The convergence of ICT has reduced the cost of doing business and also significantly reduced the cost of sharing knowledge and information (Kipkosgei, Kang, \& Choi, 2020). In Pakistan, people are now more attracted to goods and services used in western countries. The use of TV and the internet enable individuals to access goods and services used in other parts of the world and help them to adapt to changes happening around the globe. This all helps in creating fairly homogenous consumption patterns.

\section{RESEARCH GAP}

The emergence of globalization has changed the eating habits of the individual, dressing styles, ways of communication, education attainment methods, sharing and communication methods, etc. in Pakistan. The role of international trade, MNCs, ICT, education is immense in pacing up the process of globalization in Pakistan.

The present study is designed to check the impact of globalization on the consumption patterns of the people living in Punjab Pakistan.

\section{LITERATURE REVIEW}

The world is experiencing a unique form of global consumer culture where people are living in a single system. The global consumer culture is emerging where the same goods are available in the majority of the countries to consume. If not available in a country, globalization has made it very easy to get it through trade or even online purchases through the internet. According to Stearns (2006), market-led globalization has changed the dynamics of the markets and providing a wide range of goods that were not available before. The connection between globalization and consumerism was established by Rajkobal (2008). According to the author, consumers are getting an extensive range of goods due to globalization.

Consumerism is one of the main driving forces of the globalization process and has become a common characteristic of every country. The role of commerce has immense in creating consumerism. The General Agreement on Tariffs and Trade (GATT) and World Trade Organization (WTO) have stimulated free trade in the world by implementing reduced tariff rate policies for the member countries. With the introduction of GATT and WTO, Multinational Corporations (MNCs) have got freedom and dominance in the international business environment. The goods provided by MNCs can be seen in every part of the world with the same quality and these MNCs are also holding a significant share of the local market (Nefeily, 2009). In this regard, Rahman, (2007) discussed the emergence of MNCs as a result of the globalization process and how these MNCs have changed the socio-economic dynamics of the countries.

The role of ICT is immense in changing the consumption habits of the individual all over the world and especially in Pakistan. The dynamics of consumption have changed due to the introduction of online shopping which is giving pace to the global consumer culture (Cleveland \& Bartsch, 2019). The introduction of the computer, mobile phone, and internet has made it easier for the consumer to outreach many goods and services by just browsing various websites and getting information through social media networks (Kotabe \& Helsen, 2020; Lukiyanchuk, Panasenko, Kazantseva, Lebedev, \& Lebedeva, 2020). People now spend a significant share of their income on their communication needs. Many studies have highlighted that technological advancement has influenced all fields of life including food, clothing, education, health, and services in general (Ali et al., 2014; Paek \& Pan, 2004; Willcox, Dobson, \& Whittaker, 2019; Zadeh \& Mozaffari, 2014). Specifically, regarding food and clothing, a large number of studies have discussed the role of ICT in shaping consumer attitudes towards consumerism and westernization. The usage of credit and debit cards in Pakistan has increased rapidly in recent years. All these factors have driven society towards overconsumption and luxury fever which is financed by debt. In a study conducting by Siddiqui and Anjum (2013), the authors highlighted the use of credit cards has increased in Pakistan as people are using more and more credit cards for payments of purchases.

The globalization process is putting pressure on the societies to change their traditions which is destabilizing the domestic socio-economic arrangements. The same effects have been felt in Pakistan as well as people are following the western lifestyle by replacing traditional food with fast food and traditional 'Shalwar Kameen'with the jeans and a shirt. 
In this regard, Jadoon and Sarwar (2020) conducted a survey-based study and concluded that globalization has changed the lifestyle of the individuals living in Pakistan. Education institutions are playing a decisive role in giving pace to the globalization process. Access to knowledge and information is made easy through the internet in educational institutions (Holloway, Green, \& Livingstone, 2013). The parents in Pakistan prefer to send their children to English medium schools which are changing the socio-economic thoughts of the students (Manan, David, Dumanig, \& Channa, 2017). According to Paek and Pan (2004), globalization has created a global consumerism phenomenon and education is playing a significant role in developing consumerist values in Chinese people.

The review of the literature suggests that globalization is changing the consumption patterns of the individual all over the world and people in Pakistan are also experiencing the same change. Globalization, with the help of various mediums like commerce, ICT and education is changing the eating habits, dressing style, mode of communication, and purchasing methods of the people. The literature on globalization and changing consumption patterns highlighted that most of the studies have considered only one or two components of consumption among which the most popular choice seems to be fast food. To the best of the researcher's knowledge, not a single study has checked the impact of globalization on various components of consumption collectively. Moreover, the past studies on globalization and consumption patterns relationship are mostly descriptive but the present study has used more sophisticated techniques such as the structural equation model (SEM).

The past studies have primarily checked the impact of globalization on a single component of consumption but the present study has a unique importance as it will include various components of consumption while analysing the effect of globalization on consumption patterns. Figure 1 explains the determination of the variables and the relationship between globalization and consumption patterns.

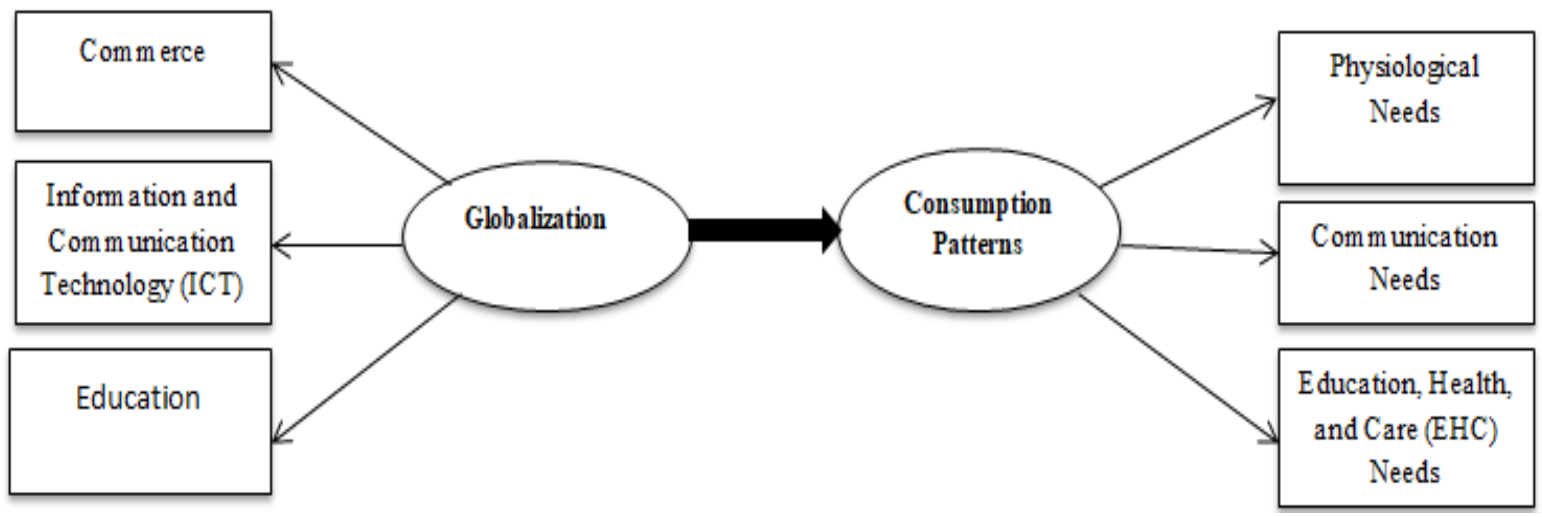

Figure 1: The Impact of Globalization on Consumption Patterns

Based on the relationship presented in figure 1, the null hypothesis for the present study is:

$\mathbf{H}_{\mathbf{0}}$ : Globalization is not bringing change in the consumption patterns of the people living in Punjab, Pakistan.

\section{METHODOLOGY}

The present study has collected primary data from three cities of Punjab, Pakistan. The quantitative research method is used to measure the characteristics of the population by using sample data. The present study has adopted a questionnaire developed by Jadoon, Butt, and Hayat (2016) ${ }^{1}$ to develop measurement models for globalization, consumption patterns, and cultural changes. The methodology for the present research is discussed as under:

\section{Population}

The present study is a rare initiative to empirically check the impact of globalization on the changing consumption patterns of individuals by taking one largest province Punjab, Pakistan. The basic reason for selecting one province of Pakistan was to create a homogenous environment that reduces the effect of external and uncontrollable variables (Ismail, Srinivas, \& Tundui, 2015). Punjab consists of 58 cities and out of these cities three cities are taken for the study. Moreover, province Punjab is divided into three regions namely Central, Northern and Southern regions and out of these three regions, one major city (according to population) from each region is selected. By doing so, Lahore city was taken from the central Punjab region; Multan city was taken from the southern Punjab region and Rawalpindi city is taken from the northern Punjab region.

\section{Sampling Technique and Sample Size}

The targeted population of the present study is employed and educated people of Punjab. The questionnaire developed for the study only includes people who are earning money and have at least fourteen years of education. The present study has applied a multi-stage sampling technique to get a response. In the first stage, Punjab is divided into three main 
regions as mentioned earlier and the biggest city from each region is taken for the study. In the second stage, each selected city is divided into various towns and then the respondent from each town is selected by using convenient sampling. Disproportionate stratified sampling is used to get the response where towns are considered as starta and respondents from each town are selected by convenient sampling. A total of 1000 sample size was taken from every three cities. Lahore city has nine towns so a sample size of 112 was taken from each town (starta). Rawalpindi has 2 towns so a sample size of 500 was taken from each of the two towns. Multan has four towns so a sample size of 250 was taken from every four towns.

\section{Reliability and Validity of the Instrument}

There are many methods to check the reliability of the instrument but the most common method is the coefficient value of Cronbach's alpha which must be greater than 0.60 (Sekaran \& Bougie, 2016). The present study has used the coefficient value of Cronbach's alpha to check the reliability of the instrument. The convergent validity of the instrument was checked by applying confirmatory factor analysis (CFA) to various latent variables. The present study has used higher-order models for the determination of latent variables namely globalization and consumption patterns. Due to the implementation of higher-order, it is unnecessary to check the discriminant validity of the instrument.

\section{Data Collection Procedure and Response Rate}

Both the paper-pencil questionnaire and a web-based questionnaire were developed. As discussed earlier, 1000 questionnaires were sent in each of three selected cities and a total of 1402 questionnaires out of 3000 were received. During the process of data screening, 81 questionnaires were excluded from the final analysis which brings the total number of final questionnaires to 1321 . The response rate from Lahore, Multan, and Rawalpindi was $46.4 \%, 43.1 \%$, and $42.6 \%$ respectively.

\section{Structural Equation Modeling (SEM)}

Over time, the use of SEM has increased in the study of consumer behaviour (Scholderer \& Grunert, 2005). According to Priester (2010), SEM is very convenient for social science research. Hox and Bechger (2007) discussed that SEM is widely used in the behavioural sciences. SEM is quite helpful when the model of the study is complex as it can run multiple regressions at the same time (Ashraf, Akhter, \& Noor, 2014). Moreover, SEM confirms the relationship between latent variables and items used to measure latent variables based on the theory or literature. The present study has also used SEM for the estimation as it will best serve the objective of the research. Before applying SEM, EFA and CFA were performed. EFA was performed on the data collected for the pilot study which helped to identify the items to measure latent variables of the study and CFA was performed on the complete data.

\section{RESULTS AND DISCUSSION}

\section{Exploratory Factor Analysis (EFA)}

EFA is conducted at the early stage of the research to determine how measurement variables (items) are measuring latent variables and which items are going together to measure different latent variables of the study. Since the present study has used an adopted questionnaire, the application of EFA is not necessary but for reconfirmation, EFA was performed on the data collected for the pilot study of 257 respondents. The minimum factor loading for each item must be 0.30 (Hair, Black, Babin, Anderson, \& Tatham, 2006). For the present study, items that have factor loading greater than 0.30 were retained for further analysis. All the twelve items used in the questionnaire to measure globalization variables were retained for further analysis of the study. Two out of sixteen items were deleted at this stage of the study due to low factor loading (factor loading less than 0.30). Moreover, the values of Cronbach's alpha were also greater than the minimum limit of 0.60 for the latent variables of the study. The Cronbach's alpha values confirmed the reliability of the instrument.

\section{Confirmatory Factor Analysis (CFA)}

CFA is a well-known form of factor analysis that is commonly used in social science research. CFA is applied on firstorder variables which are measuring a specific phenomenon and it confirms whether measurement variables are measuring that phenomenon or not. CFA also validate the understanding of the researcher about many latent variables and test the relationship between latent variables and measurement variables (Bartholomew, Knott, \& Moustaki, 2011).

Different model fit indices including Normed Chi-square (Chi-square/df ${ }^{2}$ ), CFI, IFI, GFI, RMSEA, and TLI are used to check the results of CFA and SEM. The value of Chi-square/df must be less than 5 (Kline, 2011) and the value of RMSEA must be less than 0.08 . The value of CFI, IFI, GFI, and TLI lies between 0 and 1 . The values of these fit indices must be greater than 0.90 or even 0.95 ( $\mathrm{Hu} \&$ Bentler, 1999). Standardized regression weights are used to check the factor loadings.

Moreover, the higher-order model is applied while measuring globalization and consumption pattern construct. Since the theory and results of EFA suggest that there are three dimensions for each globalization and consumption pattern 
variable, a higher-order model can be hypothesized. CFA is performed on first-order latent variables to confirm the convergent validity and then higher-order models are applied. The details are discussed as under:

\section{Globalization}
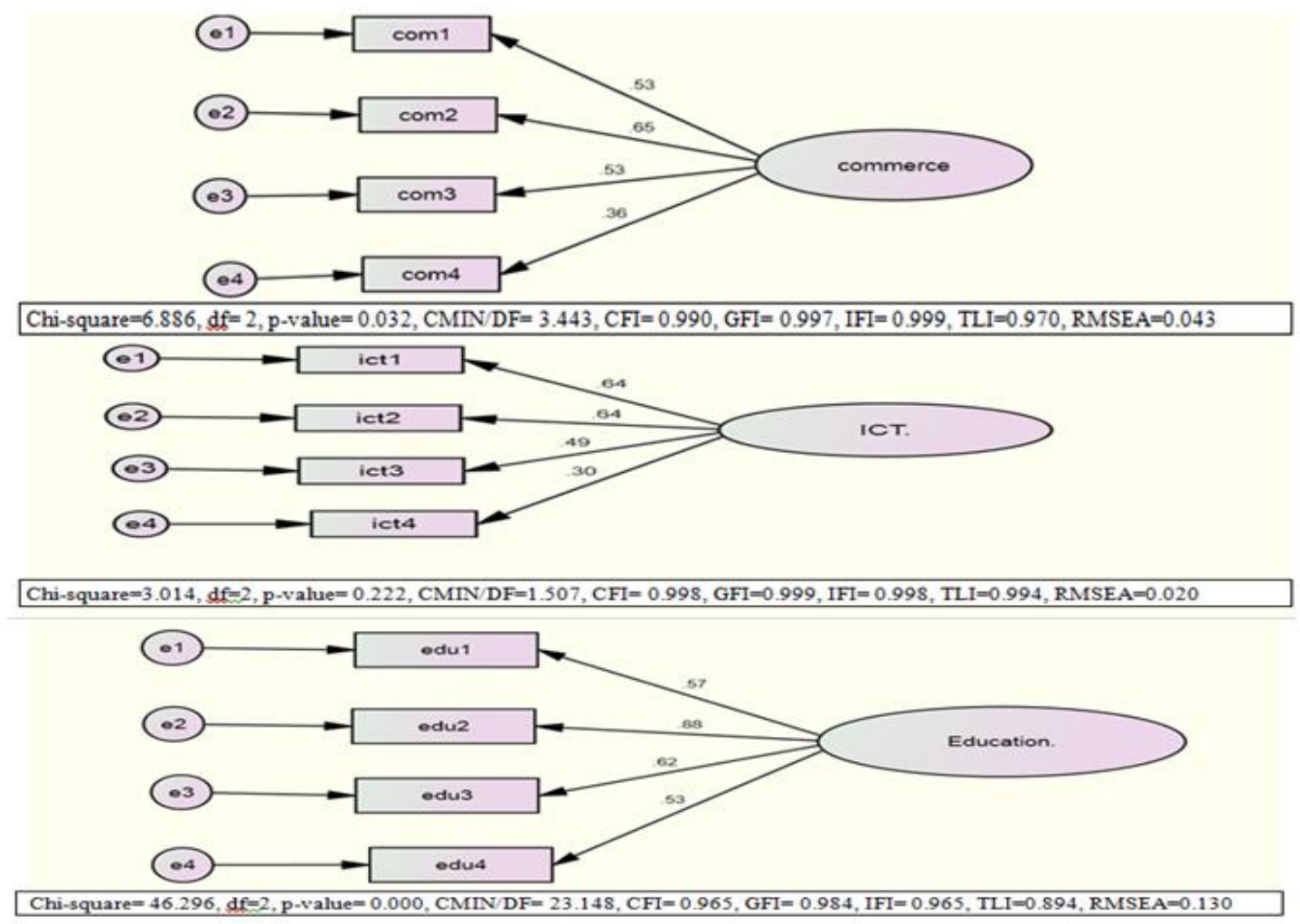

Figure 2: First Order CFA of Three Dimensions of Globalization

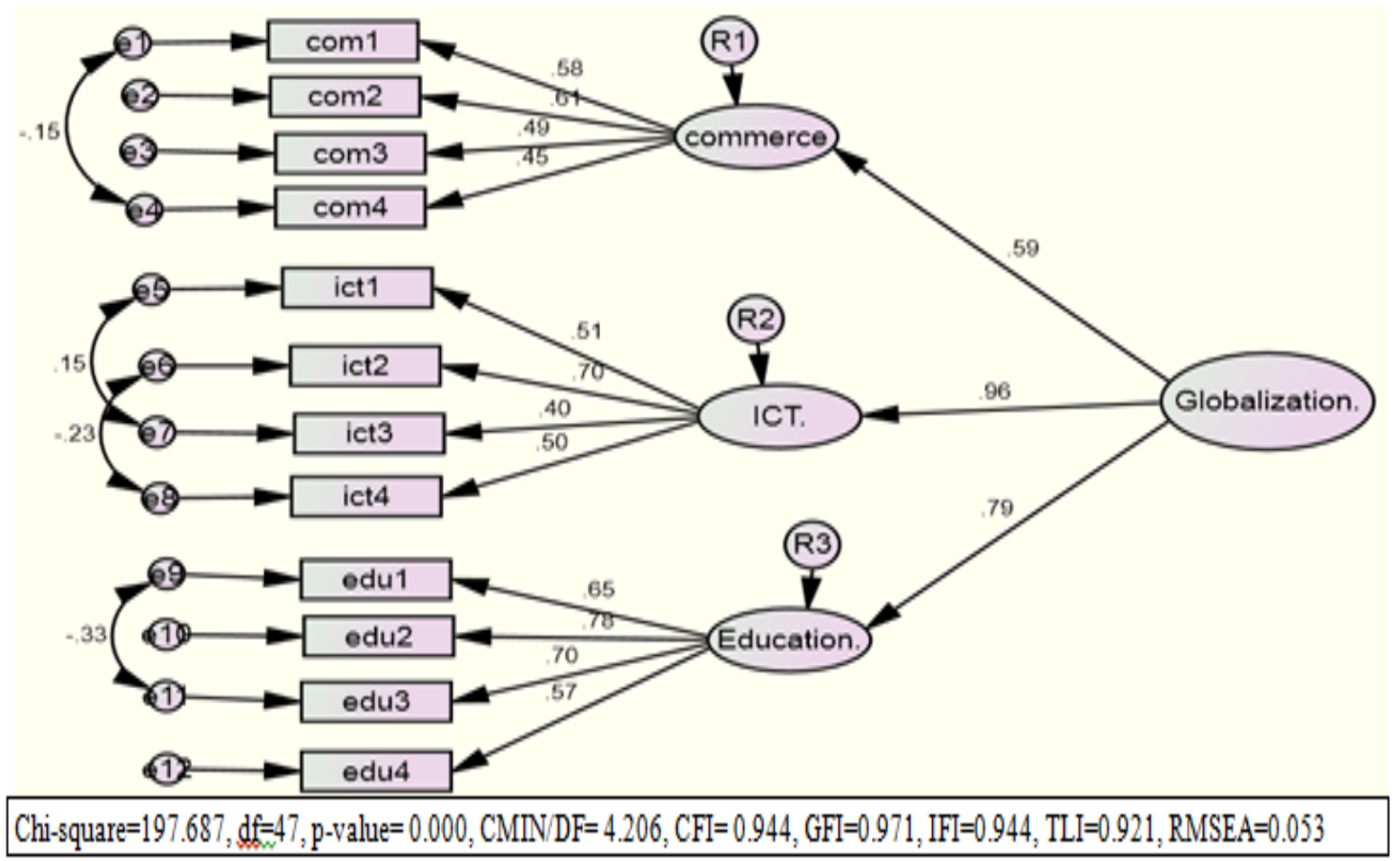

Figure 3: Higher Order CFA of Globalization

CFA is applied on three latent variables of globalization separately and then a higher-order model is applied to determine the globalization variable. The results of the CFA for the globalization variable show that models are a good fit. The value of Chi-square/df for all the models is less than the threshold level of 5 and values of RMSEA are less than 0.08 
except education construct of globalization. The values of all the other fit indices are greater than 0.90 . We can ignore a single indicator as all the other fit indices are according to the threshold level. The results of the higher-order model show that three first-order latent variables are measuring the globalization variable.

\section{Consumption Patterns}

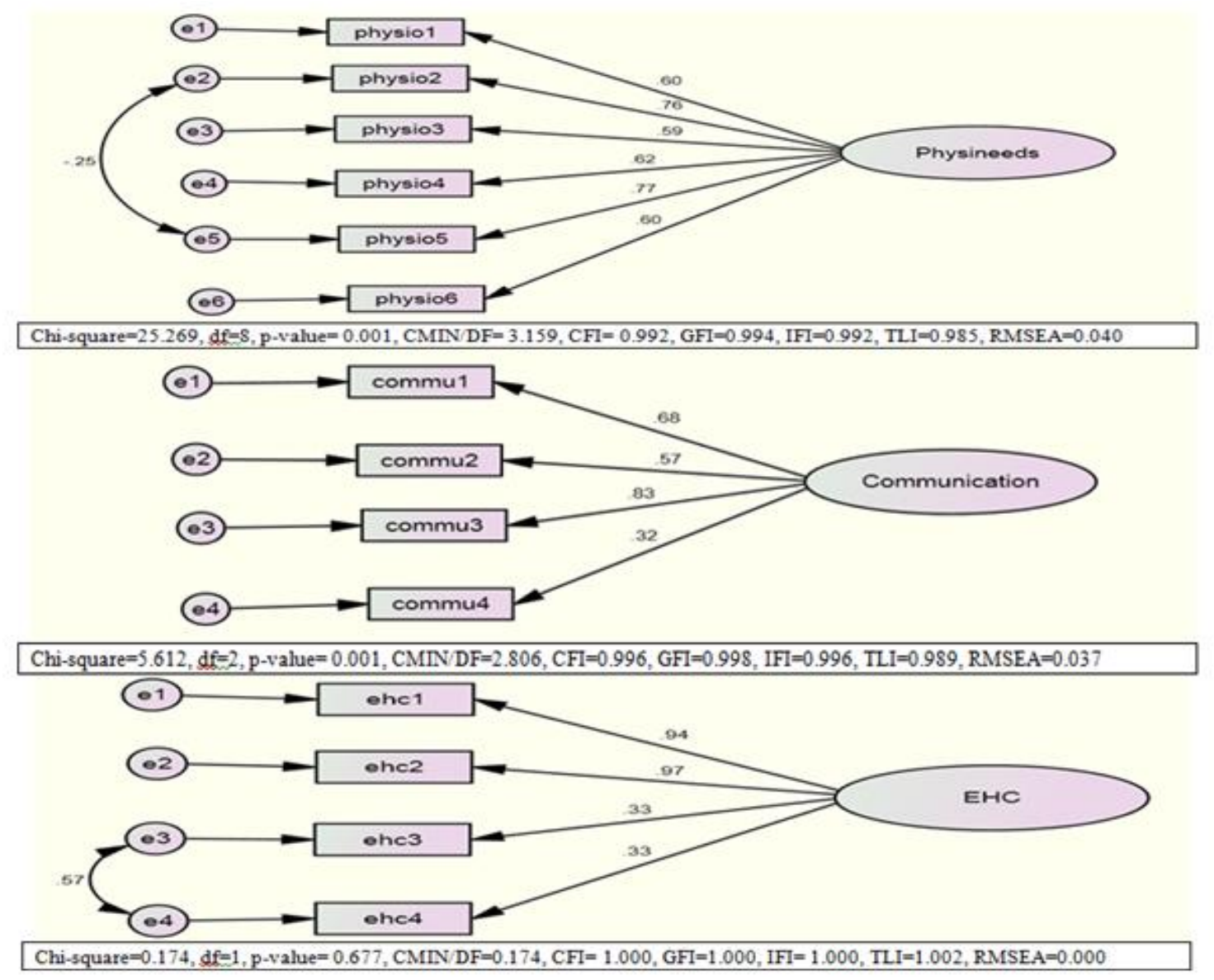

Figure 4: First Order CFA of Three Dimensions of Consumption Patterns

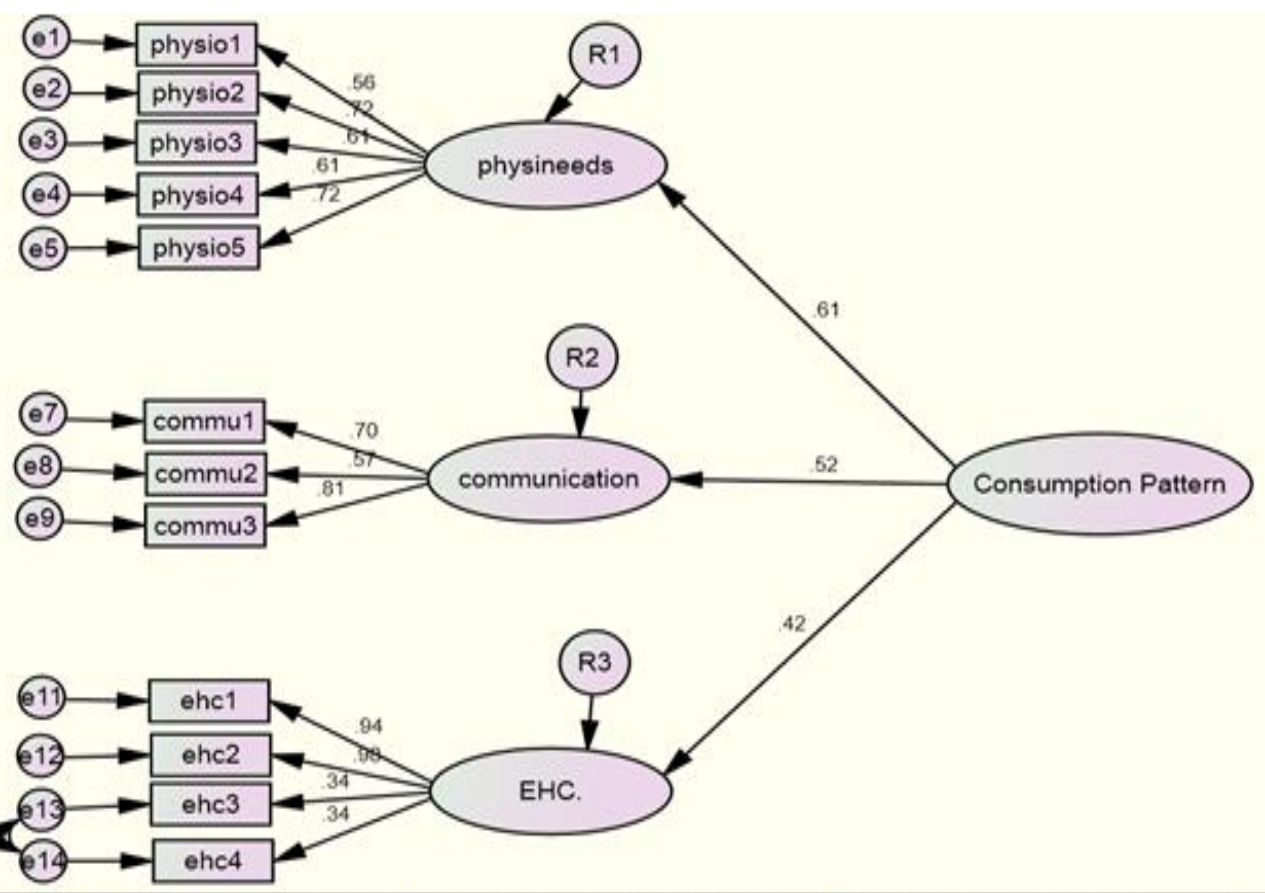

Chi-square $=193.971, \mathrm{df}=51, \mathrm{p}$-value $=0.000, \mathrm{CMIN} / \mathrm{DF}=3.8033, \mathrm{CFI}=0.955, \mathrm{GFI}=0.954, \mathrm{IFI}=0.955, \mathrm{TLI}=0.941, \mathrm{RMSEA}=0.065$

Figure 5: Higher Order CFA of Consumption Patterns 
CFA is applied separately on all three dimensions of consumption patterns (physiological needs, communication needs, and ethnic household consumption) and then higher-order CFA is applied. The results show that the values of all the fit indices are according to the threshold level. The values of Chi-square /df are less than 5 and values of RMSEA are also less than 0.08. The values of all other fit indices are greater than 0.90 . Two measurement variables namely physio6 and commu4 are deleted in the higher-order model due to low factor loading (factor loading < 0.30). The results of CFA for both globalization and consumption patterns construct pave the way to apply SEM.

\section{SEM Results and Discussion}

SEM is applied to check the effect of globalization on the consumption patterns of individuals. The same model fit indices are used in SEM as were used in CFA. Some of the measurement variables used to measure dimensions of globalization and consumption patterns variables are dropped from the final model due to low factor loadings. The measurement items ict 4 and edu4 measuring globalization variable and measurement items physio4, commu2, and ehc2 are dropped in the final SEM. The estimated model is shown in Figure 6.

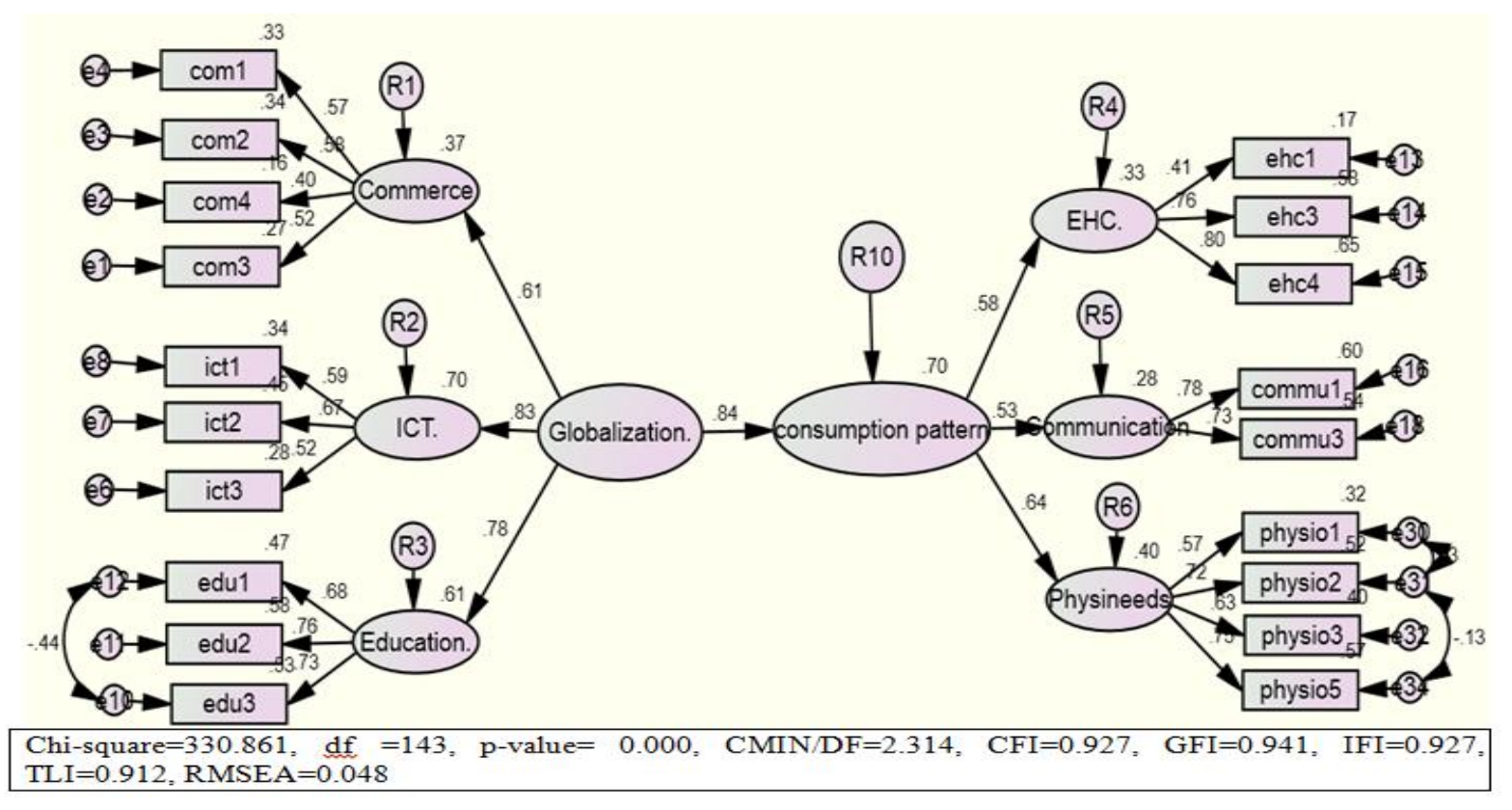

Figure 6: Impact of Globalization on Consumption Patterns

The results of the final best fitted SEM show that all the values of all the fit indices are according to the required level. The results of SEM confirm the significant effect of globalization on the consumption patterns of people. The coefficient of the standardized effect of globalization on consumption patterns is 0.84 ( $\mathrm{p}$-value $=0.0001$ ). This coefficient narrates that 0.84 standardized deviation increases in changing consumption patterns happen due to 1 standardized deviation increase in globalization. Based on the p-value, we reject the null hypothesis which states globalization is not changing consumption patterns.

The results of the present study are in line with the studies of Rahman (2007) and Yahya et al. (2013) in which researchers discussed that globalization is changing the eating patterns of individuals. Furthermore, the results of the present study also validate the study of Ali et al. (2014) in which researchers discussed the role of globalization in changing consumption patterns of clothing. Although the previous researchers have various studies on the effect of globalization on various single components of consumption patterns, the present study has brought into light the composite effect of globalization on consumption patterns in a single study.

\section{CONCLUSION AND POLICY RECOMMENDATION}

Globalization and its effects on the economy have remained one of the hot issues in socio-economic literature in recent decades. Globalization has changed the dynamics of socio-economic activities all over the world. Since globalization is a complex concept and difficult to measure, the researchers in past have used many proxies for globalization including trade volumes, capital flows, foreign investment, number of embassies in a country, number of McDonald's, etc. but all those measures were used in studies using macro-level data. Even the globalization indexes were developed for macrolevel data by taking various measures of globalization. The present study is unique in the sense that it has constructed a measure for globalization to check its impact on the consumption patterns of individuals. Moreover, in literature, not a single study has measured the globalization and consumption pattern variable with various dimensions and at the same time established the link between two variables. Moreover, the present study has also used more sophisticated techniques like EFA, CFA, and SEM to test the hypothesis of the study. 
The results of the study validated the measurement constructs for the globalization and consumption patterns variables for micro-level data. The results also highlighted the fact that globalization has greatly affected the consumption patterns of the people living in Punjab, Pakistan. The consumption patterns are driven by globalization where individuals in Pakistan are trying to follow western lifestyles by using fast food, western clothes, credit cards, etc., and by doing so they prefer to send the next generation of Pakistan to English medium schools. The result of the study also confirms that changes in consumption patterns are largely dependent on the globalization process.

The growing western fast-food industry has changed the dynamics of food consumption in Pakistan. People are now replacing the consumption of traditional food with fast food. The role of MNCs in changing consumption patterns is also noteworthy. Therefore, there is a need to streamline the policies related to these MNCs so that Pakistan can reap maximum benefit from the process of globalization. Generally, the MNCs exploit the labor in developing countries by making them work in inhumane conditions as the safety standards are usually ignored in the struggle of producing cheap goods. Although the MNCs earn excessively high profits (due to low production costs and high product prices) in developing countries, they still pay low wages in developing countries by following the local minimum wage laws. In this regard, there is a need to revise the minimum wage rate for workers working in MNCs. Furthermore, such policies should be formulated that bound the MNCs to revise their pricing policies and pass on the benefit of lower cost to the consumers.

\section{LIMITATIONS OF THE STUDY}

There are some limitations to the present study. For instance, for the present study consumption patterns of the nondurable goods are considered in this study, and the response was only taken from those respondents who are employed and have at least 14 years of education. Furthermore, only urban areas were taken for the present study as the effects of globalization are more prominent in urban areas.

\section{ACKNOWLEDGEMENTS}

We thank Prof. Dr. Hamid Bahari-Kashani, Division Chair, Business, and Economics Division, Western Oregon University, United States of America (USA), and Prof. Dr. Suleyman Degirmen, Department of Economics, Mersin University, Mersin/ Turkey for their valuable suggestions.

\section{AUTHOR'S CONTRIBUTIONS}

Atif Khan Jadoon: Conceptualization, editing of the manuscript, formal analysis and application, methodology writing, writing the original draft, and formal analysis.

Maria Faiq Javaid: Formal analysis and application, methodology writing, writing-editing of the manuscript.

Rehan Ahmed Khan: Data collection, literature survey, methodology writing.

Syeda Azra Batool: Data collection, introduction, writing-editing of the manuscript, and application.

\section{REFERENCES}

1. Ali, A., Khalid, A., \& Hassan, S. A. (2014). The impact of Indian dramas on language and dressing of females. IOSR Journal Of Humanities And Social Science (IOSR-JHSS), 19(1), 66-71. https://doi.org/10.9790/0837191116671

2. Ardalan, K. (2009). Globalization and culture: four paradigmatic views. International Journal of Social Economics,36(5), 513-534. https://doi.org/10.1108/03068290910954013

3. Ashraf, M. A., Akhter, S., \& Noor, S. I. (2014). Consumer behavior in fast food marketing in Bangladesh: a case study. Developing Country Studies, 4(9), 34-44.

4. Bartholomew, D. J., Knott, M., \& Moustaki, I. (2011). Latent variable models and factor analysis: A unified approach (Vol. 904): John Wiley \& Sons. https://doi.org/10.1002/9781119970583

5. Bigman, D. (2002). Globalization and the developing countries: Emerging strategies for rural development and poverty alleviation: Cabi. https://doi.org/10.1079/9780851995755.0000

6. Bretos, I., \& Marcuello, C. (2017). Revisiting globalization challenges and opportunities in the development of cooperatives. Annals of Public and Cooperative Economics, 88(1), 47-73. https://doi.org/10.1111/apce.12145

7. Campbell, K., Diffley, J., Flanagan, B., Morelli, B., O’Neil, B., \& Sideco, F. (2017). The 5G economy: How 5G technology will contribute to the global economy. IHS Economics and IHS Technology, 4, 16.

8. Cleveland, M., \& Bartsch, F. (2019). Global consumer culture: epistemology and ontology. International marketing review,36(4), 556-580. https://doi.org/10.1108/IMR-10-2018-0287

9. Ergashev, I., \& Farxodjonova, N. (2020). Integration of national culture in the process of globalization. Journal of Critical Reviews, 7(2), 477. https://doi.org/10.31838/jcr.07.02.90

10. Haidar, S., \& Fang, F. (2019). English language in education and globalization: A comparative analysis of the role of English in Pakistan and China. Asia Pacific Journal of Education, 39(2), 165-176. https://doi.org/10.1080/02188791.2019.1569892 
11. Hair, J. F., Black, W. C., Babin, B. J., Anderson, R. E., \& Tatham, R. (2006). Multivariate data analysis . Uppersaddle River: NJ: Pearson Prentice Hall.

12. Holloway, D., Green, L., \& Livingstone, S. (2013). Zero to eight: Young children and their internet use. LSE : London.

13. Hox, J., \& Bechger, T. (2007). An introduction to structural equation modeling. Family Review, 11, $354-373$.

14. Hu, L. t., \& Bentler, P. M. (1999). Cutoff criteria for fit indexes in covariance structure analysis: Conventional criteria versus new alternatives. Structural equation modeling: a multidisciplinary journal, 6(1), 1-55. https://doi.org/10.1080/10705519909540118

15. Islam, T., Attiq, S., Hameed, Z., Khokhar, M. N., \& Sheikh, Z. (2019). The impact of self-congruity (symbolic and functional) on the brand hate. British Food Journal, 121(1),71-88. https://doi.org/10.1108/BFJ-03-2018$\underline{0206}$

16. Ismail, I. J., Srinivas, M., \& Tundui, H. (2015). Transaction costs and market participation decisions of maize small holder farmers in Dodoma region, Tanzania. Global Journal of Biology, Agriculture and Health Sciences, 4(2), 12-20.

17. Jadoon, A. K., Butt, A. R., \& Hayat, M. A. (2016). Development of measurement models for globalization, consumption patterns and culture. Pakistan Economic and Social Review, 54(2), 327-361.

18. Jadoon, A. K., \& Sarwar, A. (2020). Is Trade Liberalisation Pro-Poor in Pakistan? Evidence from Large-Scale Manufacturing. Australian Economic Review, 53(3), 360-394. https://doi.org/10.1111/1467-8462.12360

19. Kearney, J. (2010). Food consumption trends and drivers. Philosophical transactions of the royal society B: biological sciences, 365(1554), 2793-2807. https://doi.org/10.1098/rstb.2010.0149

20. Kipkosgei, F., Kang, S.-W., \& Choi, S. B. (2020). A team-level study of the relationship between knowledge sharing and trust in Kenya: Moderating role of collaborative technology. Sustainability, 12(4), 1615. https://doi.org/10.3390/su12041615

21. Kline, R. B. (2011). Principles and practice of structural equation modeling (3. Bask1). New York, NY: Guilford.

22. Kotabe, M. M., \& Helsen, K. (2020). Global marketing management: John Wiley \& Sons.

23. Lukiyanchuk, I., Panasenko, S., Kazantseva, S., Lebedev, K., \& Lebedeva, O. (2020). Development of online retailing logistics flows in a globalized digital economy. Revista Inclusiones, 407-416.

24. Manan, S. A., David, M. K., Dumanig, F. P., \& Channa, L. A. (2017). The glocalization of English in the Pakistan linguistic landscape. World Englishes, 36(4), 645-665. https://doi.org/10.1111/weng.12213

25. Moahi, K. H. (2007). Globalization, knowledge economy and the implication for indigenous knowledge. The International Review of Information Ethics, 7, 55-62.

26. Nefeily, S. E.-D. A. (2009). It is Dialogue'not Clash: Al Manhal.

27. Paek, H.-J., \& Pan, Z. (2004). Spreading global consumerism: Effects of mass media and advertising on consumerist values in China. Mass Communication \& Society, 7(4), 491-515. https://doi.org/10.1207/s1532 7825mcs0704_7

28. Priester, J. R. (2010). The use of structural equation models in Consumer Psychology: a methodological dialogue on its contributions, cautions, and concerns. Journal of Consumer Psychology, 20(2), 205-207. https://doi.org/10.1016/j.jcps.2010.03.005

29. Rahman, K. (2007). MNCs and TNCs: Their role and socioeconomic impact on host societies. Policy Perspectives, 115-126.

30. Rahman, T. (2006). Language policy, multilingualism and language vitality in Pakistan. Lesser known languages of South Asia: Status and policies, case studies and applications of information technology, 73-106.

31. Rajkobal, P. (2008). Globalization, consumerism, and unsustainable consumption. Reterived from https://www.majortests.com/essay/Globalization-Consumerism-and-Unsustainable-Consumption-F3SZ5VGQA A. html

32. Robertson, R. (1992). Globalization: Social theory and global culture (Vol. 16): Sage.

33. Rosokhata, A. S., Rybina, O. I., Derykolenko, A. O., \& Makerska, V. (2020). Improving the classification of digital marketing tools for the industrial goods promotion in the globalization context. Research in World Economy, 11(4),42-52. https://doi.org/10.5430/rwe.v11n4p42

34. Scholderer, J., \& Grunert, K. G. (2005). Consumers, food and convenience: The long way from resource constraints to actual consumption patterns. Journal of Economic Psychology, 26(1), 105-128. https://doi.org/10.1016/j.joep.2002.08.001

35. Sekaran, U., \& Bougie, R. (2016). Research methods for business: A skill building approach: John Wiley \& Sons.

36. Sharma, R., Nguyen, T. T., \& Grote, U. (2018). Changing consumption patterns-Drivers and the environmental impact. Sustainability, 10(11), 4190. https://doi.org/10.3390/su10114190

37. Siddiqui, K., \& Anjum, M. (2013). Perceptions towards credit card usage: Factor analytic finding from Pakistan. International Journal of Economics Business and Management Studies-IJEBMS, 2(3), 128-135.

38. Stearns, P. N. (2006). Consumerism in world history: The global transformation of desire: Routledge. https://doi.org/10.4324/9780203969885

39. Steger, M. B. (2017). Globalization: A very short introduction (Vol. 86): Oxford University Press. https://doi.org/10.1093/actrade/9780198779551.001.0001 
40. Sundaram, J. K., \& Khoo, K. J. (2003). Globalization and its discontents, Revisited: Tulika.

41. Surugiu, M.-R., \& Surugiu, C. (2015). International trade, globalization and economic interdependence between European countries: Implications for businesses and marketing framework. Procedia Economics and Finance, 32, 131-138. https://doi.org/10.1016/S2212-5671(15)01374-X

42. Tabish, M., Hussain, S. F., \& Afshan, S. (2017). Factors that affect brand loyalty: A study of mobile phone industry of Pakistan. KASBIT Business Journal (KBJ), 10, 151-170.

43. Ulucak, R., Koçak, E., Erdoğan, S., \& Kassouri, Y. (2020). Investigating the non-linear effects of globalization on material consumption in the EU countries: Evidence from PSTR estimation. Resources Policy, 67, 101667. https://doi.org/10.1016/j.resourpol.2020.101667

44. Usman, A., Javed, M., Amjad, A., Jalil, A., Shaheen, I., \& Amjad, U. (2017). Food, City and Young Globavores: perceptions of Pakistani urban youth about food choices and healthy eating. The Anthropologist, 27(1-3), 143-151. https://doi.org/10.1080/09720073.2017.1311681

45. Wang, H., Shi, P., \& Zhang, Y. (2017). Jointcloud: A cross-cloud cooperation architecture for integrated internet service customization. Paper presented at the 2017 IEEE 37th international conference on distributed computing systems (ICDCS). https://doi.org/10.1109/ICDCS.2017.237

46. Willcox, J. C., Dobson, R., \& Whittaker, R. (2019). Old-fashioned technology in the era of "Bling": is there a future for text messaging in health care? Journal of medical Internet research, 21(12), e16630. https://doi.org/10.2196/16630

47. Yahya, F., Zafar, R., \& Shafiq, S. (2013). Trend of fast food consumption and its effect on Pakistani society. Food Science and Quality Management, 11, 1-7.

48. Zadeh, E. G., \& Mozaffari, A. (2014). The impact of satellite TV channels on lifestyle changes for women in Iran. International journal of business and social science, 5(3), 126-131.

49. Zeb, H., Rashid, K., \& Javeed, M. B. (2011). Influence of brands on female consumer's buying behavior in Pakistan. International Journal of Trade, Economics and Finance, 2(3), 225. https://doi.org/10.7763/ IJTEF.2011.V2.107 